\title{
The heart failure in Internal Medicine in Tuscany: the SMIT Study
}

\author{
Valerio Verdiani, ${ }^{1}$ Grazia Panigada, ${ }^{2}$ Alberto Fortini, ${ }^{3}$ Luca Masotti, ${ }^{4}$ Simone Meini, ${ }^{5}$ Paolo Biagi ${ }^{6}$ \\ for the SMIT Study Group \\ ${ }^{1}$ Internal Medicine Department, Misericordia Hospital (GR); ${ }^{2}$ Internal Medicine Department, SS. Cosma e Damiano Hospital, \\ Pescia (PT); ${ }^{3}$ Internal Medicine Department, S. Giovanni di Dio Hospital, Scandicci (FI); ${ }^{4}$ Internal Medicine Department, \\ S. Maria Nuova Hospital, Firenze; ${ }^{5}$ Internal Medicine Department, S. Maria Annunziata Hospital, Bagno a Ripoli (FI); \\ ${ }^{6}$ Internal Medicine Department, Nottola Hospital, Montepulciano (SI), Italy
}

\begin{abstract}
The incidence and prevalence associated with the growing age of population have made heart failure (HF) a new epidemic. In Italy most of HF patients are admitted to Internal Medicine Departments (IMD). We conducted a 30-day cross-sectional study involving patients with HF admitted to IMD of Tuscany. The aim of the study was to provide an updated snapshot of in-hospital management of HF in Tuscany and to analyze the differences in relation to the most recent guidelines. We have recruited 770 patients $(\mathrm{M}=45.4 \%)$ with a mean age of $82.5 \pm 8.9$ years. Only $16.1 \%$ had a de novo HF. Most of them were re-admitted for decompensated HF. Hypertension and ischemic disease are the prevailing etiologies. HF alone was in less than $2 \%$. $71.5 \%$ of patients had more than two comorbidities and $40.6 \%$ more than three concomitant diseases. The mean hospital stay (overall $8.6 \pm 5.5$ days) correlated with the number of comorbidity. About $25 \%$ of patients had a creatinine clearance $<30 \mathrm{~mL} / \mathrm{min}$. Nearly $50 \%$ of patients had atrial fibrillation but only the half was anti-coagulated. $\beta$-blockers, angiotensin converting enzyme-inhibitors (ACE-I) or angiotensin receptor blockers (ARB) were prescribed in about two-thirds of the subjects. Echocardiography was performed in $64.1 \%$ of patients. BNP or NT-pro BNP was tested in $67 \%$ at the hospital admission and in $18.3 \%$ at the discharge. At the discharge $50.1 \%$ of patients had loss of autonomy, $57 \%$ a polypharmacy prescription ( $\geq 8$ classes of medicines) and $21.2 \%$ needed domiciliary oxygen therapy, but despite these critical points only $8 \%$ of the patients were transferred to long-term/intermediate care settings. In conclusion, the main characteristics of patients with HF admitted to IMD in Tuscany are the advanced age (the patients are old and very old) and the presence of multiple comorbidities (HF alone is a rarity indeed). The use of echocardiography and the pharmacological therapy with ACE-I, ARB, $\beta$-blocker and anti-aldosterone agents is wider than previous surveys, but some diagnostic, therapeutic and prognostic aspects are not similar to that recommended by the most recent HF guidelines. This survey underscores again some differences between HF trials world and HF real world, where the management is probably also driven by a clinical holistic approach.
\end{abstract}

Correspondence: Valerio Verdiani, via Faccioli 15, 50145 Firenze, Italy. Tel.: +39.366.6581380 - Fax: +39.0564 .48533 . E-mail: verdiani@fastwebnet.it

Paolo Biagi, Internal Medicine Department, Nottola Hospital, 53045 Montepulciano (SI), Italy. Tel.: +39.340.6293252 Fax: +39.0578 .716422 .

E-mail: chipama@libero.it; paolobiagi48@libero.it

Key words: Heart failure; Tuscany.

See online Appendix for Centers participating in the SMIT (Scompenso Cardiaco in Medicina Interna in Toscana) Study Group.

Received for publication: 22 October 2014.

Revision received: 19 January 2015.

Accepted for publication: 19 October 2015.

This work is licensed under a Creative Commons Attribution NonCommercial 3.0 License (CC BY-NC 3.0).

CCopyright V. Verdiani et al., 2015

Licensee PAGEPress, Italy

Italian Journal of Medicine 2015; 9:349-355

doi:10.4081/itjm.2015.554

\section{Introduction}

Chronic heart failure (CHF) develops as a result of left ventricular (LV) systolic and/or diastolic dysfunction. ${ }^{1}$ The ageing of the global population and the availability of effective treatments in patients with acute coronary syndromes prolong survival, so the incidence of CHF is increasing ${ }^{2,3}$ and the number of patients at risk of developing this condition is expected to grow. ${ }^{4,5}$ In Italy it is estimated that in 2050 life expectancy for 65 -year-old people will be about 30 years more $^{6}$ and we know that CHF is a predictor of mortality also in the elderly and very elderly patients. ${ }^{7}$

Until a few years ago epidemiological data on CHF came from observational or registry studies in settings of Cardiology Departments. ${ }^{8-11}$ The characteristics of these patients in many ways are similar to those of the HF trials designed for younger subjects without comorbidities. ${ }^{12,13}$

It is about a decade that in Italy we have data of the HF impact within Internal Medicine Departments (IMD). In Italy, most of the patients hospitalized for HF is discharged by these Departments ${ }^{14}$ and it is pos- 
sible to ascertain that they are similar to the so-called real world, i.e., old or very old patients, most often frail, with multiple comorbidities. Their management is often different from that of the trials and it is not always possible to fully apply the recommendations of HF guidelines.

We performed an observational study in IMD of Tuscany, an Italian region characterized by a mean age of population higher than the mean of Italy. ${ }^{15}$ With the aim to record the epidemiological and clinical data and to analyze the differences of the HF management in relation to the most recent guidelines.

\section{Materials and Methods}

Most of Tuscany IMD (32 of 36) took part in the study. We enrolled patients who were discharged by departments in a period of 30 days $\left(30^{\text {th }}\right.$ January- $28^{\text {th }}$ February 2014) with the main diagnosis of HF. Diagnosis was performed on the ground of clinical/instrumental/laboratory data. ${ }^{16}$ For each patient had to be filled a data sheet consisting of separate sections: in the first section in addition to the personal demographic data it was defined the Department of origin (Emergency room, Intensive Brief Observation, Coronary Intensive Care Unit, Intensive Therapy Departments), if it was a de novo $\mathrm{HF}$, if the patient was admitted within 30 days and/or within 1 year with the same diagnosis; in the second section were recorded clinical data, HF etiology, the New York Heart Association (NYHA) class at admission; in the third one were recorded the instrumental and laboratory data such as BNP-NT-pro BNP (admission and discharge), echocardiography (no. of examinations performed), if the examination had been carried out by the internist or cardiologist, stratification of left ventricular ejection fraction (LVEF) computed by Simpson method; ${ }^{17}$ in the fourth section was recorded the therapy generically defined in classes of drugs [angiotensin converting enzyme-inhibitors (ACE-I), angiotensin receptor blockers (ARBs), $\beta$ blockers, calcium antagonists, ivabradin, digoxin, antialdosterone agents, warfarin, new oral anticoagulants (NOA), antiplatelet drugs, statins]; in the fifth were analyzed the comorbidities (number, prevalence and severity); in particular we studied chronic renal failure (stratified according to the glomerular filtration rate calculated by the Cockroft-Gault formula), diabetes mellitus (defined as previous diagnosis, or specific therapy, or blood glucose greater than $126 \mathrm{mg} / \mathrm{dL}$ ), arterial hypertension regardless of severity, clinically defined chronic obstructive pulmonary disease, active cancer (if cancer was a relevant part of the clinic at the time of recruitment), anemia defined according to the criteria of the World Health Organization (WHO $)^{18}$ and in particular moderate/severe anemia defined as anemia with hemoglobin $(\mathrm{Hb})<10 \mathrm{~g} / \mathrm{dL}$; in the sixth sec- tion were taken into consideration: outcome, hospital mortality, critical situation at the discharge (loss of autonomy, need of domiciliary oxygen therapy, discharge at long-term care, geriatric wards/intermediate care, prescription of more than 7 classes of medicines), definition of follow-up programs (cardiac rehabilitation units, designed home care program, in-hospital followup program).

\section{Statistics}

The data were analyzed by calculating averages (mean+standard deviation) of continuous numeric variables or percentages for not-continuous ones. In some cases, a transformation was applied in not-continuous variable in order to define a clinical severity (mild, moderate and severe) score.

Numeric variables were compared by Student's $t$ test. Discrete variables were summarized by frequency percent and compared by the chi-square test.

Linear regression analysis using the least square method was employed to correlate the length of staying and the number of comorbidities. A P value $<0.05$ was considered statistically significant.

Statistical analyses were carried out by using SAS software (version 9.1; SAS Institute, Cary, NC, USA).

\section{Results}

We have taken into consideration 770 patients (341 males $=45.4 \%$. $\mathrm{P}<0.001)$ aged $82.5 \pm 8.9$ years, including $708(91.7 \%)$ over 70 years old. Near $70 \%(68.3 \%)$ are over 80 and nonagenarians are over $15 \%(\mathrm{M}=50$ vs $\mathrm{F}=103 ; \mathrm{P}<001)$.

The admission to IMD of the patients came from emergency settings in almost all cases (91.7\%), in $4.2 \%$ from intensive coronary care unit, in the remaining $4.1 \%$ from other departments. Only 121 cases represented de novo HF (16.1\%), the others were admitted due to worsening of HF. One hundred and seventy patients $(22.6 \%)$ had another admission for the same cause during the previous 30 days.

The etiology of the HF is for the most part ischemic and/or hypertensive (Figure 1).

At admission to hospital, over eighty-three percent of the subjects were in NYHA class III/IV (mean NYHA class was $3.1 \pm 0.74)$.

The clinical and the most significant instrumental and laboratory data $(\mathrm{Hb}$, creatinine, BNP/NT pro-BNP and echocardiography) are shown in Table 1 . More in detail echocardiography was performed in $64.1 \%$ of the patients. Preserved LVEF ( $>50 \%$ ) was present in $40.2 \%$, a marked depressed ventricular ejection fraction (LVEF $<35 \%$ ) in $28.6 \%$ of the population studied.

BNP or NT pro-BNP was tested in 516 patients $(67 \%)$ at admission (mean value: BNP $1197 \pm 2436$ 
$\mathrm{pg} / \mathrm{mL}$; NT pro-BNP $8776 \pm 9474 \mathrm{pg} / \mathrm{mL}$ ) and in 133 $(18.3 \%)$ at discharge (mean value: BNP $1103 \pm 1757$ $\mathrm{pg} / \mathrm{mL}$; NT pro-BNP $7416 \pm 8818 \mathrm{pg} / \mathrm{mL}$ ). In only 114 patients (15.7\%) BNP or NT pro-BNP was measured both at admission and at discharge.

Atrial fibrillation (AF) was present in 423 (47\%) of patients $(\mathrm{M}=244$ vs $\mathrm{F}=179 ; \mathrm{P}<0.01)$.

The prevalence and the number of comorbidities is shown in Table $2 .{ }^{17,19} \mathrm{HF}$ alone was present in less than $2 \% ; 71.5 \%$ of patients had more than two comorbidities and as much as $40.6 \%$ more than three concomitant diseases; a previous transient ischemic attack or stroke or a symptomatic peripheral vascular disease were recorded in $29 \%$ of cases.

The cardiovascular therapy is resumed in Table 3.

Overall mean hospital stay was $8.63 \pm 5.5$ days and average length of staying (LOS) in IMD was 7.92 \pm 4.8 . The length of staying (Table 4) showed a gradual increase according to the number of comorbidities both in hospital and in IMD (Figure 2); this was particularly evident in those who had more than four comorbidities for which they had a significant higher LOS both in hospital and in IMD than the other patients who had a lower number of concomitant diseases.

In-hospital mortality was $5.9 \%$ (45 patients), more in detail 21 males $(5.4 \%)$ and 24 females $(7.8 \%)(\mathrm{P}$; not significant) died. 58 patients (8\%) were transferred to long-term care settings, more in detail 36 males $(9.7 \%)$ and 22 females $(6.7 \%)$ (P; not significant).

The most important criticalities at the discharge are summarized in Table $5 .{ }^{20}$

\section{Discussion}

Heart failure is a real problem in western countries: life expectancy is progressively rising and this goes pari passu with the reduction of mortality related to acute ischemic heart disease. So we may expect that over the next years the overall burden of HF (economic, social) will increase.

Our survey was performed in an Italian Region, Tuscany, characterized by a higher prevalence of elderly than the rest of Italy (mean age 45.45 vs 43.50 years, respectively). ${ }^{18}$

In our study the population is old, the mean age being over 82 years old, three female patients were over 100. Compared with precedent studies in Italy ${ }^{21-23}$ we may notice that from 2002 the mean age of the patients with HF has increased over 5 years.

According to the most recent guidelines, ${ }^{16,24}$ echocardiography had a more wider use than that of previous surveys in IMD, ${ }^{21,23}$ irrespective of the fact that the examination is performed from an internist or a cardiologist.

Our data confirm that in an old population the form of $\mathrm{HF}$ with preserved systolic function is prevalent. ${ }^{25,26}$
We considered the cardiovascular treatment in relation to the adherence to the International guidelines suggestions: about two-thirds of the subjects were in therapy with ACE-I or ARB, a figure not so high like that of recent cardiologic surveys ${ }^{27,28}$ but higher enough, taken into account the age of our population, and the well-known problems linked to their tolerance in this age group.

Moreover $25 \%$ of our subjects presented a marked reduction in creatinine clearance $(<30 \mathrm{~mL} / \mathrm{min})$ and this may have conditioned a wider use of this class of drugs.

\section{"ISCHEMIC " HYPERTENSIVE $\equiv$ VALVULAR $\equiv$ OTHER}

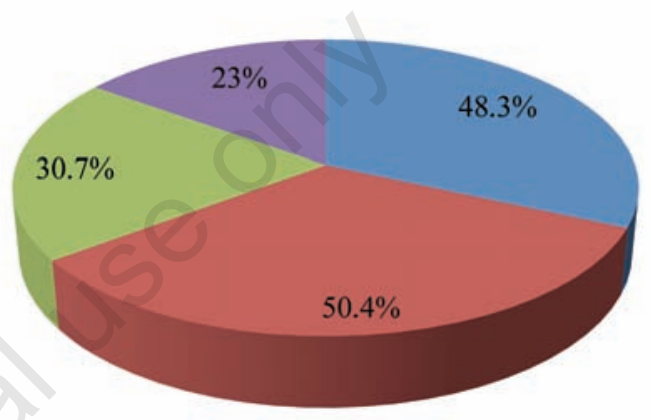

Figure 1. Etiology of heart failure. Note that percent is over one hundred since in many cases the etiology of heart failure is multiple.

Table 1. Clinical, instrumental and laboratory characteristics of the patients admitted to Internal Medicine Departments.

\begin{tabular}{lc}
\hline Parameter & Value \\
\hline NYHA class & $3.1 \pm 0.74$ \\
\hline NYHA 2 & $14.9 \%$ \\
\hline NYHA 3 & $46.8 \%$ \\
\hline NYHA 4 & $32.2 \%$ \\
\hline Creatinine & $46.64 \pm 24.34$ \\
\hline Creatinine/clearance $<30 \mathrm{~mL}$ min & $25.3 \%$ \\
\hline Hb g/dL & $11.98 \pm 2.0$ \\
\hline Hb $<10$ g/dL & $14.6 \%$ \\
\hline Beats/min & $77.47 \pm 12.71$ \\
\hline LVEF & $44.09 \pm 12.25$ \\
\hline LVEF $>50 \%$ & $38.6 \%$ \\
\hline LVEF $<35 \%$ & $18.3 \%$ \\
\hline BNP pg/mL & $1197+2436$ \\
\hline NT pro-BNP pg/mL & $8776+9474$ \\
\hline $\begin{array}{l}\text { NYHA, New York Heart Association; } \text { Hb, hemoglobin; } \text { LVEF, left ventricular ejection } \\
\text { fraction. }\end{array}$
\end{tabular}


More patients than before ${ }^{21,23}$ are treated $\beta$-blockers, especially the patients with reduced systolic function, in fact about three out of four patients with LVEF $<40 \%$ are in $\beta$-blocker treatment. This is in good accord with the most recent suggestion of International guidelines: ${ }^{24}$ taking into account the characteristics of our population this means that internist are now more trained to use these drugs in patients in which their safety (i.e., the therapeutic range) may be reduced. ${ }^{29}$
One in two patients with LVEF $<35 \%$ was treated with anti-aldosterone agents: this figure can be explained by the concomitant use ACE-I/ARBs in an old patient which could lead to life-threatening hyperkalemia as previously reported. ${ }^{30}$ Ivabradine was prescribed in only $17.6 \%$ of the patients in sinus rhythm. We suppose that this low figure may depend first on the low heart rate of our patients (secondary to the widened use of $\beta$-blockers?) and on the fact that this drug is a

Table 2. Comorbidities and differences by gender.

\begin{tabular}{|c|c|c|c|c|c|}
\hline Comorbidities & No. & $\%$ & М\% & F\% & $\mathbf{X}$ \\
\hline Arterial hypertension & 559 & 72.6 & 30.1 & 41.6 & ns \\
\hline Diabetes mellitus & 269 & 35.8 & 17.5 & 17.5 & ns \\
\hline COPD & 269 & 35.8 & 18.7 & 16.7 & ns \\
\hline Moderate/severe renal dysfunction (creatinine/clearance <60 mL/min) & 554 & 71.9 & 41.1 & 30.7 & ns \\
\hline Cognitive impairment* & 236 & 31.4 & 10.2 & 20.6 & 0.05 \\
\hline Anemia $^{\circ}$ & 425 & 44.2 & 26.3 & 28.9 & ns \\
\hline Anemia with $\mathrm{Hb}<10 \mathrm{~g} / \mathrm{dL}$ & 110 & 14.6 & 7.9 & 6.3 & ns \\
\hline Active cancer & 50 & 6.6 & 3.6 & 3.5 & ns \\
\hline
\end{tabular}

ns, not significant; COPD, chronic obstructive pulmonary disease; Hb, hemoglobin. ${ }^{*}$ Cognitive impairment=Pfeiffer test $<7 ;{ }^{19}{ }^{\circ} \mathrm{M}<13 \mathrm{~g} / \mathrm{dL} \mathrm{F}<12 \mathrm{~g} / \mathrm{dL} .{ }^{17}$

Table 3. Medications list at admission and at discharge.

\begin{tabular}{|c|c|c|c|}
\hline & $\begin{array}{c}\text { Admission } N=770 \\
\%\end{array}$ & $\begin{array}{c}\text { Discharge } N=721 \\
\%\end{array}$ & $\mathbf{P}$ \\
\hline ACE-I & 43.6 & 49.4 & 0.05 \\
\hline $\mathrm{ARB}$ & 19.8 & 15.0 & 0.01 \\
\hline $\mathrm{ACE}$ or $\mathrm{ARB}$ in $<40 \% \mathrm{LVEF}$ & 71 & 67.7 & ns \\
\hline$\beta$-blockers & 51.7 & 67.8 & 0.001 \\
\hline$\beta$-blockers in $<40 \% \mathrm{LVEF}$ & 61 & 76.7 & 0.001 \\
\hline Diuretics & 78.0 & 91.4 & 0.001 \\
\hline Ivrabradine & 2.5 & 5.4 & 0.005 \\
\hline Anti-aldosterone agents & 21.4 & 37.5 & 0.001 \\
\hline Anti-aldosterone agents in LVEF $<35 \%$ & 32.1 & 25.0 & ns \\
\hline Digoxin & 13 & 14.7 & ns \\
\hline Warfarin & 26.6 & 27.4 & ns \\
\hline Warfarin in aa ff & 40.9 & 42.0 & ns \\
\hline NOA & 4.0 & 4.4 & ns \\
\hline Anti-platelet & 45.5 & 51.2 & 0.001 \\
\hline Anti-platelet in aa ff & 35.6 & 37.2 & ns \\
\hline Statins & 28 & 31 & ns \\
\hline Ca-blockers & 16 & 14.4 & $\mathrm{~ns}$ \\
\hline No. of other drugs & 3.2 & 4.1 & ns \\
\hline
\end{tabular}


relative new entry in the therapeutic scenario of HF treatment. Digoxin use is almost exclusive (90\%) in patients with AF. Near one out of two patients has AF.

$\mathrm{CHA}_{2} \mathrm{DS}_{2}$-VASc score ${ }^{31}$ identifies our patients at high risk of thromboembolism but anticoagulant therapy is present only in half of the cases of the patients with AF. It is possible that the age factor, other comorbidities such as cognitive impairment or active cancer or, on the whole, high HAS-BLED score ${ }^{32}$ may have played a role even though the characteristic of the subjects of our study should have suggested a more extended use. NOA are still marginally used.

Our patients have many comorbidities, their prevalence is similar to that of previous surveys, and from our data the number of comorbidities is correlated with the mean hospital stay. Our study was not retailed to define the prognostic impact of each comorbidity but it is well known that renal failure, anemia and cognitive deficit are the worse prognostic factors of $\mathrm{HF}$ in an elderly population. ${ }^{21,23}$

Also BNP or NT pro-BNP are powerful prognostic markers: above all their discharge values are good predictors of hospital readmission, ${ }^{33-35}$ but their determination was uncommon in our study.

Concerning the patients discharged from the wards we found many critical elements. First of all about one third of population has cognitive impairment and one half is not self-sufficient: this makes difficult to take care of them. And this is especially true if we consider that more than a half of patients must take over 8 drugs a day, a marker of multiple pathologies, and over $20 \%$ need oxygen. It is probable that the percentage of patients temporary assigned to lower intense settings of care is still minimal for the needs of this population.

Another admission for the same cause during the previous 30 days was present in $22.6 \%$ of patients. Although our aim was not to define the most used and useful follow up program, we have registered that $40 \%$ of patients were discharged with a well-stated one and this could contribute to lower the rolling doors phenomenon.
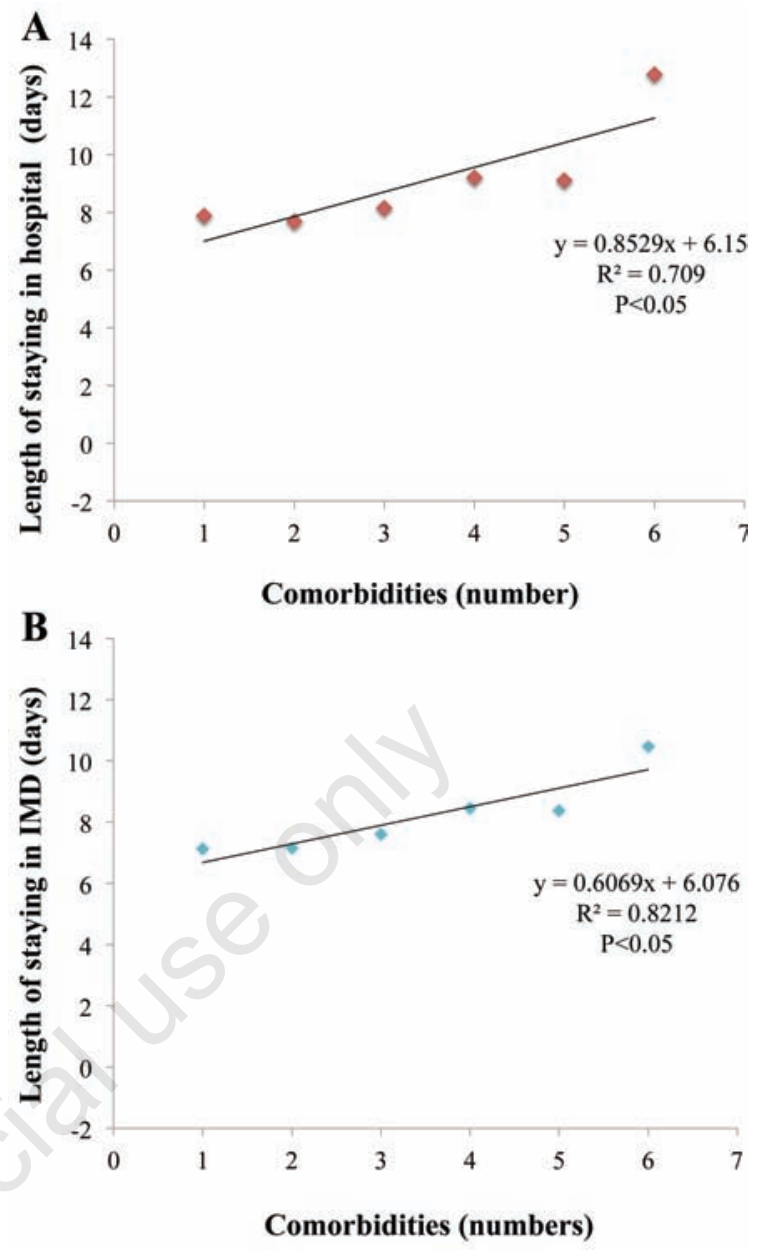

Figure 2. A) Length of staying (LOS) in hospital according to the number of comorbidities in patients admitted for heart failure. The LOS in hospital was statistically longer in patients with more than 4 comorbidities $(9.46+6.05$ days vs $8.60+5.53$ days, respectively; $P<0.05)$; B) LOS in Internal Medicine Departments (IMD) according to the number of comorbidities in patients admitted for heart failure. The LOS to IMD was statistically longer in patients with more than 4 comorbidities $(8.62+4.99$ vs $7.96+4.91$ days; $\mathrm{P}<0.05)$.

Table 4. Number of comorbidities and length of staying in hospital and in the Internal Medicine Departments. Two patients had more than 6 comorbidities so they were not calculated.

\begin{tabular}{lccc}
\hline No. of comorbidities & No. of patients & LOS in hospital (mean+SD) & LOS in IMD (mean+SD) \\
\hline 0 & 8 & $10.25 \pm 5.73$ & $7.5 \pm 5.02$ \\
\hline 1 & 61 & $7.88 \pm 4.10$ & $7.13 \pm 3.95$ \\
\hline 3 & 151 & $7.68 \pm 5.26$ & $7.15 \pm 4.64$ \\
\hline 4 & 240 & $8.15 \pm 5.20$ & $7.89 \pm 4.93$ \\
\hline 5 & 198 & $9.21 \pm 4.97$ & $8.46 \pm 4.56$ \\
\hline
\end{tabular}

LOS, length of staying; SD, standard deviation; IMD, Internal Medicine Departments. 
Table 5. Critical situations at discharge.

\begin{tabular}{lc}
\hline Criticality & Total number (\%) \\
\hline Loss of autonomy* $^{*}$ & $354(50.1)$ \\
\hline Domiciliary oxygen therapy $^{\circ}$ & $150(21.2)$ \\
\hline Prescription of more than $>7$ drugs & $403(57.0)$ \\
\hline * Loss of autonomy means a Barthel index score of 40 or less, ${ }^{20}{ }^{\circ}$ Need of oxygen for \\
more than two hours a day.
\end{tabular}

\section{Conclusions}

Our study represents a snapshot of HF in IMD in Tuscany; it shows that the patients admitted for HF to IM wards have become older and have many comorbidities. The number of comorbidities is correlated with the mean hospital stay.

The use of echocardiography and the pharmacological therapy with ACE-I, ARB, $\beta$-blocker and anti-aldosterone agents is wider than previous surveys in similar population and settings, but some diagnostic, therapeutic, prognostic elements are not still similar to that recommended by the most recent HF guidelines.

We must take into account that no trial has been made and no guidelines have been drawn up in the very old patients and that the treatment of HF in complex patients like those admitted to IMD is often driven by a clinical holistic approach. We are confident that surveys concerning real world of HF patients admitted to IMD will contribute to improve their care.

\section{References}

1. Remme WJ, Swedberg K; The Task Force for the Diagnosis and Treatment of Chronic Heart Failure of the European Society of Cardiology. Guidelines for the diagnosis and treatment of chronic heart failure. Eur Heart J 2000;22:1527-60.

2. Gibbs LM, Addington-Hall J, Gibbs JS. Dying from heart failure: lessons from palliative care. Many patients would benefit from palliative care at the end of their lives. BMJ 1998;317:961-2.

3. McMurray J, McDonagh T, Morrison CE, Dargie HJ. Trends in hospitalization for heart failure in Scotland 1980-1990. Eur Heart J 1993;14:1158-62.

4. Tendera M. Epidemiology, treatment, and guidelines for the treatment of heart failure in Europe. Eur Heart $\mathrm{J}$ 2005; 7:J5-9.

5. Huovinen E, Harkanen T, Martelin T, et al. Predicting coronary heart disease mortality-assessing uncertainties in population forecasts and death probabilities by using Bayesian inference. Int J Epidemiol 2006;35: 1246-52.

6. Stranges M. L'invecchiamento demografico in Italia: verso un miglioramento della relazione tra età e lavoro. Quaderni europei sul nuovo welfare. Available from: http://www.newwelfare.org/2007/02/25/1'invecchia- mento-demografico-in-italia-verso-un-miglioramentodella-relazione-tra-eta-e-lavoro/

7. Formiga F, Ferrer A, Mascarò J, et al. Predictive items of one year mortality in nonagenarians. The Nonasanfeliu study. Aging Clin Exp Res 2007;19:265-8.

8. The SEOSI Investigators. Surveys on heart failure in Italian hospital cardiology units. Results of the SEOSI study. Eur Heart J 1997;18:1457-64.

9. Maggioni AP, Schweiger C, Tavazzi L, et al. Epidemiologic study of use of resources in patients with unstable angina: the EARIA registry. Am Heart J 2000;140:253-63.

10. Pulignano G, Del Sindaco D, Tavazzi L, et al. Clinical features and outcomes of elderly outpatients with heart failure followed up in hospital cardiology units: data from a large nationwide cardiology database (IN-CHF Registry). Am Heart J 2002;143:45-55.

11. Maggioni AP. IN-CHF: il registro italiano dello scompenso cardiaco. Dieci anni di esperienza. G Ital Cardiol 2006;7:689-94.

12. Pfeffer MA, Swedberg K, Granger CB, et al. Effects of candesartan on mortality and morbidity in patients with chronic heart failure: the CHARM-Overall program. Lancet 2003;362:759-66.

13. McMurray JJV, Östergren J, Swedberg K, et al. for the CHARM Investigators and Committees Effects of candesartan in patients with chronic heart failure and reduced left-ventricular systolic function taking angiotensin converting- enzyme inhibitors: the CHARM-Added trial. Lancet 2003;362:767-71.

14. Cacciatore P, Ceccolini C, Granella P, et al. Analisi dei ricoveri per insufficienza cardiaca in Italia. Anni 20012003. Roma: Ministero della salute; Aprile 2007. Available from: http://www.salute.gov.it/imgs/C_17_ pubblicazioni_663_allegato.pdf

15. UrbiStat srl. Classifica e mappa tematica della "ETÀ MEDIA" nelle Regioni; 2015. Available from: http:// www.urbistat.it/AdminStat/it/it/classifiche/eta-media/regioni/italia/380/1

16. Mc Murray JJV, Adamopoulos S, Anker SD, et al. ESC Guidelines for the diagnosis and treatment of acute and chronic heart failure 2012. Eur Heart J 2012;33:1787-847.

17. Feigenbaum H. Echocardiography. 5th ed. Philadelphia, PA: Lea and Febiger; 1994. pp 134-180.

18. [No authors listed]. Nutritional anaemias. Report of a WHO Scientific Group. World Health Organ Tech Rep Ser 1968;405:5-37.

19. Pfeiffer E. A short portable mental status questionnaire for the assessment of organic brain deficit in elderly patients. J Am Geriatr 1975;23:433-41.

20. Mahoney FI, Barthel DW. Functional evaluation: the Barthel index. Md State Med J 1965;14:61-5.

21. Di Lenarda A, Scherillo M, Maggioni AP, et al. Current presentation and management of heart failure in cardiology and internal medicine hospital units: a tale of two worlds - the TEMISTOCLE study. Am Heart J 2003; 146:E12.

22. Biagi P, Abate L, Alessandri M, et al. Heart failure with preserved systolic function: prevalence and clinical features in a cohort of patients admitted to internal medicine units. The study PRESYF-HF Tuscany. Monaldi Arch Chest Dis 2007;68:165-9.

23. Biagi P, Gussoni G, Iori I, et al. Clinical profile and predictors of in-hospital outcome in patients with heart fail- 
ure: The FADOI "CONFINE" Study and on behalf of the CONFINE Study Group. D Int J Cardiol 2011;152:88-94.

24. Yancy CW, Jessup M, Bozkurt B, et al. 2013 ACCF/AHA Guideline for the management of heart failure: a report of the American College of Cardiology Foundation/American Heart Association task force on Practise Guidelines. Circulation 2013;128:240-327.

25. Hogg K, Swedberg K, McMurray J. Heart failure with preserved left ventricular systolic function: epidemiology, clinical characteristics, and prognosis. J Am Coll Cardiol 2004;43:317-27.

26. Owan TE, Hodge DO, Herges RM, et al. Trends in prevalence and outcome of heart failure with preserved ejection fraction. N Engl J Med 2006;355:251-9.

27. Nieminen MS, Brutsaert D, Dickstein K, et al. EuroHeart Failure Survey II (EHFSII): a survey on hospitalized acute heart failure patients: description of population. Eur Heart J 2006;22:2725-36.

28. Komajda M, Hanon O, Hochadel M, et al. Contemporary management of octogenarian hospitalized for heart failure in Europe: EuroHeart Failure Survey II. Eur Heart J 2009;30:478-86.

29. Gambassi G, Forman DE, Lapane KL, et al. Management of heart failure among very old persons living in long-term care: has the voice of trials spread? The SAGE Study Group. Am Heart J 2000;139:85-93.
30. Pitt B, Zannad F, Remme WJ, et al. The effect of spironolactone on morbidity and mortality in patients with severe heart failure. N Engl J Med 1999;341:709-17.

31. Lip GY, Nieuwlaat R, Pisters R, et al. Refining clinical risk stratification for predicting stroke and thromboembolism in atrial fibrillation using a novel risk factorbased approach: the euro heart survey on atrial fibrillation. Chest 2010;137:263-72.

32. Pisters R, Lane DA, Nieuwlaat R, et al. A novel userfriendly score (HAS-BLED) to assess 1-year risk of major bleeding in patients with atrial fibrillation: the Euro Heart Survey. Chest 2010;138:1093-100.

33. Verdiani V, Nozzoli C, Bacci F, et al. Pre-discharge B type natriuretic peptide predicts early recurrence of decompensated heart failure in patients admitted to a general medical unit. Eur J Heart Fail 2005;7:566-71.

34. Logeart D, Thabut G, Jourdain P, et al. Predischarge Btype natriuretc peptide assay for identifying patients at high risk of re-admission after decompensated heart failure. J Am Coll Cardiol 2004;43:635-41.

35. Pfisterer M, Buser P, Rickli H, et al. BNP-guided vs symptom-guided heart failure therapy: the Trial of Intensified vs standard medical therapy in Elderly patients with Congestive Heart Failure (TIME-CHF) randomized trial. JAMA 2009;301:383-92. 